\title{
SACHÊS ABSORVEDORES DE ETILENO NA PÓS-COLHEITA DE MAÇÃS 'ROYAL GALA'
}

\author{
CASSANDRO VIDAL TALAMINI DO AMARANTE² \& CRISTIANO ANDRÉ STEFFENS ${ }^{3}$
}

RESUMO - A redução dos níveis de etileno no ambiente de armazenamento é importante na preservação da qualidade pós-colheita de frutos. O presente trabalho teve por objetivo avaliar o efeito de sachês contendo pellets $(10 \mathrm{~g})$ impregnados com absorvedor de etileno à base de permanganato de potássio $\left(\mathrm{KMnO}_{4}\right)$, na preservação da qualidade pós-colheita de maçãs 'Royal Gala' armazenadas em câmara fria e em temperatura ambiente. O emprego de um ou dois sachês de produto, durante o armazenamento refrigerado convencional (dois meses a $0 \pm 0,5^{\circ} \mathrm{C} / 90-95 \%$ de UR) dos frutos, acondicionados em caixas de $18 \mathrm{~kg}$, envoltos em filme de polietileno de alta densidade $(30 \mu \mathrm{m})$, reduziu a concentração de etileno no interior da embalagem. Isto ocasionou maior retenção de cor verde na casca e de firmeza de polpa e menor incremento no teor de sólidos solúveis nos frutos, especialmente após uma semana de comercialização simulada $\left(20 \pm 4^{\circ} \mathrm{C} / 70-80 \%\right.$ de UR). Em temperatura ambiente, a utilização de um sachê de produto por caixa reduziu a concentração de etileno no interior das embalagens de polietileno e retardou o amadurecimento dos frutos em relação ao tratamentocontrole, sendo este efeito mais expressivo em frutos colhidos em estádios menos avançados de maturação. Os resultados obtidos mostram que o absorvedor de etileno à base de $\mathrm{KMnO}_{4}$ representa uma alternativa viável para a preservação da qualidade de maçãs 'Royal Gala', imediatamente após a colheita, durante o transporte refrigerado, na exportação de maçãs, bem como durante a comercialização, em temperatura ambiente. Termos para indexação: Malus domestica Borkh., permanganato de potássio, estádio de maturação, armazenamento, qualidade de frutos.

\section{ETHYLENE ABSORPTION SACHETS IN POSTHARVEST OF 'ROYAL GALA'APPLES}

\begin{abstract}
The reduction of ethylene levels in the storage environment is important for postharvest preservation of fruit quality. This research was carried out to assess the effects of ethylene absorption with sachets containing pellets $(10 \mathrm{~g})$ impregnated with potassium permanganate $\left(\mathrm{KMnO}_{4}\right)$ on postharvest quality preservation of 'Royal Gala' apples under refrigerated and ambient temperature storage. The addition of one or two sachets of product, for fruits packed in standard cartons boxes (18kg of fruits), lined with high density polyethylene film $(30 \mu \mathrm{m})$, reduced ethylene inside the package during two months of conventional cold storage (at $0 \pm 0.5^{\circ} \mathrm{C} / 90-95 \% \mathrm{RH}$ ). This led to a better retention of skin background color and flesh firmness and a smaller increase of soluble solids content in the fruits, especially after one week of shelf life $\left(20 \pm 4^{\circ} \mathrm{C} / 70-80 \% \mathrm{RH}\right)$. Under ambient temperature, the use of one sachet per box reduced ethylene concentration inside the package and retarded fruit ripening compared to the control treatment. These effects were more evident in fruit harvested in a less advanced maturity stage. The results show that ethylene absorption with $\mathrm{KMnO}_{4}$ is a viable alternative to preserve postharvest quality of 'Royal Gala' apple, immediately after fruit harvest, during cold storage transportation of exported fruit, as well as during fruit retail at ambient temperature.
\end{abstract}

Index terms: Malus domestica Borkh., potassium permanganate, maturity stage, storage, fruit quality.

\footnotetext{
'(Trabalho 084-08). Recebido em: 03-04-2008. Aceito para publicação em: 13-01-2009.

${ }^{2}$ Ph.D., Bolsista de Produtividade em Pesquisa do CNPq, Professor do Departamento de Agronomia, Centro de Ciências Agroveterinárias (CAV), Universidade do Estado de Santa Catarina (UDESC), Lages-SC. Autor para correspondência. Email: amarante@cav.udesc.br

${ }^{3}$ Dr., Professor do Departamento de Agronomia, UDESC/CAV, Lages-SC. E-mail: steffens@cav.udesc.br
} 


\section{INTRODUÇÃO}

A área de fisiologia e tecnologia pós-colheita tem apresentado avanços substanciais, visando a reduzir as perdas quantitativas e qualitativas que ocorrem em frutos durante as atividades de classificação, armazenamento e comercialização (Wills et al., 1998; Kader, 2002; Chitarra \& Chitarra, 2005). Para reduzir estas perdas, é necessário melhorar os processos de manejo pós-colheita e conhecer a biologia e os fatores ambientais envolvidos na deterioração, bem como as tecnologias que retardam a senescência e preservam a qualidade dos frutos.

O etileno é o principal promotor da maturação em frutos (Kader, 2002; Chitarra \& Chitarra, 2005). O emprego do armazenamento refrigerado, associado ao uso de atmosfera controlada/modificada (Wills et al., 1998; Kader, 2002), bem como o tratamento dos frutos com inibidores da síntese (por ex., aminoetoxivinilglicina) e da ação (por ex., 1metilciclopropeno) do etileno (Watkins, 2006; Rongcai \& David, 2007) preservam a qualidade póscolheita em frutos.

O controle do etileno e de seus efeitos na maturação podem ser obtidos colhendo os frutos em estádio pré-climatérico e armazenando-os em ambiente contendo produtos capazes de remover este fitormônio. Sachês contendo pellets impregnados com permanganato de potássio $\left(\mathrm{KMnO}_{4}\right)$ promovem a oxidação do etileno à água, gás carbônico, dióxido de manganês e potássio (Wills \& Warton, 2004). Tem sido demonstrado que a utilização de pellets impregnados com $\mathrm{KMnO}_{4}$ para a remoção do etileno retarda o amadurecimento de diversos frutos climatéricos, tais como banana (Chauhan et al., 2006), kiwi (Zhang, 2002), manga (Illeperuma \& Jayasuriya, 2002), abacate (Illeperuma \& Nikapitiya, 2002), nêspera (Campos et al., 2007), caqui (Ferri e Rombaldi, 2004), pêra-japonesa (Szczerbanik et al., 2004) e maçãs (Shorter et al., 1992; Brackmann et al., 1995 e 2006).

O presente trabalho teve por objetivo avaliar o efeito de sachês contendo absorvedor de etileno à base de $\mathrm{KMnO}_{4}$, na preservação da qualidade póscolheita de maçãs 'Royal Gala' armazenadas em câmara fria e em temperatura ambiente.

\section{MATERIAL E MÉTODOS}

\section{Experimento 1 - Armazenamento refrigerado}

Este experimento foi conduzido visando a avaliar a eficiência do emprego de sachês contendo $10 \mathrm{~g}$ de pellets impregnados com $\mathrm{KMnO}_{4}$ na absorção de etileno e na preservação da qualidade pós-colheita de maçãs 'Royal Gala' durante armazenamento refrigerado

O experimento foi realizado em uma empresa comercial, no município de Lages-SC, em 2006. Maçãs 'Royal Gala' foram colhidas na maturação comercial, apresentando pelo menos $50 \%$ da superfície dos frutos com coloração vermelha e acondicionadas em bandejas de papelão, as quais foram colocadas em caixas de $18 \mathrm{~kg}$, sendo as bandejas com os frutos envoltas em filme de polietileno de alta densidade $(30 \mu \mathrm{m})$. Foram utilizados frutos com calibre 135 (127-141 g), sendo selecionados frutos livres de danos mecânicos e podridões.

As caixas de frutos foram divididas em três lotes, correspondendo aos tratamentos-controle (sem adição de sachê) e com a adição de um ou dois sachês. Foi utilizado o delineamento experimental inteiramente casualizado, com cinco repetições e cada repetição correspondendo a uma caixa contendo $18 \mathrm{~kg}$ de frutos.

Os frutos foram armazenados em câmara fria convencional $\left(0 \pm 0,5^{\circ} \mathrm{C} / 90-95 \%\right.$ de umidade relativa) durante dois meses. As avaliações de cor de fundo da casca, firmeza da polpa, sólidos solúveis (SS; 'Brix), índice de iodo-amido e acidez titulável (AT) foram feitas na implantação do experimento, um dia após a remoção dos frutos da câmara fria e após sete dias de comercialização simulada (em condição ambiente de $20 \pm 4^{\circ} \mathrm{C} / 70-80 \%$ UR). A avaliação da cor de fundo da casca foi feita com o auxílio de uma tabela de cores em escala de 1 a 7 , sendo 1: verdeescuro; 2 : verde-claro; 3 : verde muito claro; 4: verdeamarelado; 5: amarelo- esverdeado; 6: amarelo-claro e 7: amarelo. A firmeza da polpa (libras) foi quantificada com o uso de penetrômetro modelo Effegi, munido de ponteira de $11,1 \mathrm{~mm}$. O teor de SS foi quantificado com o uso de refratômetro com compensação automática de temperatura. $\mathrm{O}$ índice de iodo-amido foi avaliado numa escala de 1 (toda a superfície corada com iodo, correspondendo à predominância de amido e fruto imaturo) a 5 (toda a superfície não corada com iodo, correspondendo à predominância de açúcares solúveis e fruto totalmente maduro). Em amostras compostas de suco extraídas de cinco frutos foram feitas as determinações de AT através de titulometria de neutralização com $\mathrm{NaOH}(0,1 \mathrm{~N})$, até $\mathrm{pH} 8,1$.

A concentração de etileno (ppm) no interior das caixas de frutos, referentes aos diferentes tratamentos, foi determinada através da retirada de duas amostras de $1 \mathrm{~mL}$ de ar do interior da embalagem, ao final do período de armazenamento refrigerado (dois meses) e injetadas em um 
cromatógrafo a gás $\operatorname{Varian}^{\circledR}$ (modelo CP 3800), equipado com metanador, detector de ionização de chama e coluna Porapaq N (80 a 100 mesh). As temperaturas do forno, do detector, do metanador e do injetor foram de $45 ; 120 ; 300$ e $110^{\circ} \mathrm{C}$, respectivamente. Os fluxos de $\mathrm{N}_{2}, \mathrm{H}_{2}$ e ar utilizados foram de 70; 30 e $300 \mathrm{~mL} \mathrm{~min}^{-1}$, respectivamente.

\section{Experimento 2 - Armazenamento a temperatura ambiente}

Este experimento foi conduzido para avaliar a preservação da qualidade pós-colheita de maçãs 'Royal Gala' colhidas em diferentes estádios de maturação (Figura 2) em condições ambiente pela remoção do etileno com o emprego de sachê contendo $10 \mathrm{~g}$ de pellets impregnados com $\mathrm{KMnO}_{4}$.

$\mathrm{O}$ experimento foi conduzido junto ao Laboratório de Fisiologia Vegetal do Centro de Ciências Agroveterinárias, em Lages-SC, no ano de 2006. Maçãs 'Royal Gala' foram colhidas em quatro épocas, durante o período de colheita comercial, nos dias 28-02, 06-03, 12-03 e 18-03, correspondendo aos estádios de maturação $1 ; 2 ; 3$ e 4, respectivamente. Os frutos correspondentes aos diferentes estádios de maturação foram acondicionados em caixas de $18 \mathrm{~kg}$, envoltas em filme de polietileno de alta densidade $(30 \mu \mathrm{m})$, com ou sem adição de um sachê de produto. As caixas de frutos foram deixadas à temperatura ambiente $\left(20 \pm 2^{\circ} \mathrm{C} / 70-80 \%\right.$ UR), durante sete dias, simulando a comercialização. Foi utilizado o delineamento experimental inteiramente casualizado, com cinco repetições, cada repetição correspondendo a uma caixa contendo $18 \mathrm{~kg}$ de frutos, cada caixa (com 135 frutos).

Na colheita e ao final do período de comercialização simulada, foram feitas avaliações dos frutos através de determinações de cor de fundo da casca, firmeza da polpa, SS, índice de iodo-amido e AT, como descrito no experimento 1 .

A concentração de etileno (ppm) no interior das caixas de frutos referentes aos diferentes tratamentos foi determinada ao final do período de armazenamento, conforme descrito no experimento 1.

\section{Análise estatística dos dados}

Os dados coletados foram analisados estatisticamente usando o programa SAS (Learning Edition). As médias de tratamentos foram comparadas pelo teste LSD, a 5\% de probabilidade.

\section{RESULTADOS E DISCUSSÃO}

O uso de um ou dois sachês de permanganato de potássio em caixas com $18 \mathrm{~kg}$ de maçãs 'Royal Gala' reduziu significativamente a concentração de etileno no interior das embalagens de polietileno $(9,0$ e 8,0 ppm, respectivamente) em relação ao tratamentocontrole (17,9 ppm), na avaliação realizada ao final do período de armazenamento, porém não houve diferença significativa entre os tratamentos com um ou dois sachês.

A redução na concentração de etileno com o emprego de um ou dois sachês de produto no interior das embalagens ocasionou maior retenção de cor verde na casca e de firmeza de polpa e menor incremento no teor de SS ( ${ }^{\circ}$ Brix) nos frutos, especialmente após uma semana de comercialização simulada (Figura 1). Não houve diferença significativa entre os tratamentos com um ou dois sachês de produto para estes atributos (Figura 1). Para o índice de iodo-amido e AT, não houve efeito dos tratamentos (dados não apresentados).

Em maçãs 'Granny Smith' acondicionadas em embalagens de polietileno $(40 \mu \mathrm{m})$ e armazenadas em câmara fria convencional $\left(5^{\circ} \mathrm{C}\right)$, a utilização de absorvedor de etileno à base de $\mathrm{KMnO}_{4}$ reduziu a concentração de etileno, ocasionando assim redução nas severidades de "bitter pit" e escaldadura superficial, avaliadas após uma semana de vida de prateleira (Shorter et al., 1992). Em maçãs 'Fuji' armazenadas em condições de AC (1-3\% de $\mathrm{O}_{2}+0$ $3 \%$ de $\mathrm{CO}_{2}$ ) durante oito meses, a remoção de etileno com produto à base de $\mathrm{KMnO}_{4}$ resultou em frutos com maiores valores de firmeza de polpa e de acidez titulável (Brackmann et al., 1995). Brackmann et al. (2006), trabalhando com maçãs 'Gala' previamente armazenadas em câmara fria durante um mês, observaram que o acondicionamento de frutos em filmes de polietileno (de alta densidade, com espessura de $7 \mu \mathrm{m}$, e de baixa densidade, com espessura de $20 \mu \mathrm{m}$ ), em caixas de $18 \mathrm{~kg}$, reduziu a concentração de etileno no interior da embalagem durante 15 dias, a $4^{\circ} \mathrm{C}$, e mais três dias, a $20^{\circ} \mathrm{C}$. No entanto, a redução dos níveis de etileno não apresentou efeito significativo nos atributos qualitativos dos frutos, o que, segundo os autores, resultou do curto período de armazenamento refrigerado (15 dias) e do estádio de maturação dos frutos no momento da embalagem. Portanto, para maior eficiência de sachês contendo absorvedor de etileno à base de $\mathrm{KMnO}_{4}$, os frutos devem ser colhidos e imediatamente acondicionados em sacos de polietileno para armazenamento em câmara fria. Frutos armazenados durante certo tempo em câmara fria, 
anterior ao acondicionamento em caixas contendo o sachê com o produto comercial, por apresentarem maior produção e sensibilidade ao etileno, podem não apresentar resposta positiva na preservação da qualidade durante armazenamento refrigerado (Brackmann et al., 2006).

No experimento conduzido em condição ambiente, maçãs 'Royal Gala' foram colhidas em diferentes estádios de maturação, para então serem submetidas aos tratamentos com e sem sachê contendo absorvedor de etileno à base de $\mathrm{KMnO}_{4}$.

A colheita dos frutos em intervalos de seis dias, durante o período de colheita comercial, resultou em evolução na maturação, avaliada através da determinação da cor de fundo da casca, firmeza de polpa e índice de iodo-amido (Figura 2).

O emprego de um sachê de permanganato de potássio nas caixas contendo $18 \mathrm{~kg}$ de frutos reduziu significativamente a concentração de etileno no interior das embalagens de polietileno em relação ao tratamento-controle, em todos os estádios de maturação (Figura 3). Houve aumento substancial na concentração de etileno no interior das embalagens com o atraso da colheita (Figura 3), mostrando aumento na produção autocatalítica de etileno nos frutos colhidos tardiamente. Somente em frutos colhidos nos estádios de maturação 1 e 2, o emprego do sachê reduziu a concentração de etileno para níveis inferiores a 10 ppm. Nos frutos colhidos nos estádios de maturação 3 e 4, o sachê reduziu a concentração de etileno em relação aos tratamentos sem sachê, mas, ainda assim, a concentração de etileno foi alta (entre 30 e 70 ppm nas embalagens com um sachê).

A redução substancial na concentração de etileno no interior das embalagens contendo um sachê de $\mathrm{KMnO}_{4}$, em maçãs colhidas nos estádios de maturação 1 e 2 (correspondentes aos frutos menos maduros), resultou em significativa retenção de firmeza de polpa e menor incremento no teor de SS ( ${ }^{\circ}$ Brix) nos frutos, ao final de uma semana de manutenção dos frutos em temperatura ambiente (Figura 2). A retenção de cor verde na casca e o menor índice de iodo-amido durante armazenamento em temperatura ambiente com a utilização de sachê de $\mathrm{KMnO}_{4}$ foi significativa apenas em frutos colhidos no estádio de maturação 1 (Figura 2).

A colheita das maçãs em estádios menos avançados de maturação, ou seja, anterior à produção autocatalítica de etileno, resulta em benefícios maiores do emprego de sachês com $\mathrm{KMnO}_{4}$ em condições ambiente, pois o atraso na data de colheita resulta em rápida evolução do amadurecimento dos frutos (Kader, 2002). No caso de frutos em adiantado estádio de maturação, a elevada produção autocatalítica de etileno dificulta a eficiente remoção de etileno para níveis que não induzam os processos de amadurecimento e senescência. Nestas condições, a taxa de produção de etileno nos frutos supera gradativamente a taxa de absorção deste hormônio pelos pellets impregnados com $\mathrm{KMnO}_{4}$, levando a um maior acúmulo de etileno no interior das embalagens.

Estes resultados demonstram que o estádio de maturação dos frutos interfere na eficiência do sachê de $\mathrm{KMnO}_{4}$ em retardar a maturação de maçãs 'Royal Gala' acondicionadas em embalagens de polietileno, em caixas de $18 \mathrm{~kg}$ de frutos, durante armazenamento em temperatura ambiente. Frutos colhidos em avançado estádio de maturação produzem maiores quantidades de etileno quando mantidos à temperatura ambiente, e, desta forma, a absorção de etileno pelos pellets impregnados com $\mathrm{KMnO}_{4}$, apesar de efetiva, não possibilita a redução na concentração de etileno no ambiente de armazenamento para níveis abaixo daquela que desencadeia o amadurecimento dos frutos. Portanto, a concentração mais alta de etileno nas embalagens de frutos colhidos tardiamente ocasiona a rápida maturação das maçãs.

A redução nos níveis de etileno no ambiente de armazenamento retarda o amadurecimento e a senescência dos frutos, sendo que uma concentração de etileno no ar $\geq 0,1 \mathrm{ppm}$ já é considerada suficiente para desencadear este tipo de resposta em tecidos de plantas (Kader, 2002). Todavia, estudos recentes demonstraram que qualquer nível de etileno no ar é considerado deletério ao produto, ocorrendo decréscimo linear na vida pós-colheita com o aumento no valor do $\log _{10}$ [concentração de etileno] (Wills et al., 2001). Portanto, a remoção do etileno com o emprego de absorvedor à base de $\mathrm{KMnO}_{4}$ auxilia na preservação da qualidade pós-colheita dos frutos, como observado em maçãs 'Royal Gala' (Figuras 1 e 2). Frutos colhidos na maturação comercial e imediatamente acondicionados em filmes de polietileno, em caixas contendo $18 \mathrm{~kg}$ de frutos, com apenas um sachê de produto comercial, apresentaram melhor conservação da qualidade durante armazenamento em câmara fria, em relação ao tratamento-controle. Portanto, este produto pode ser utilizado durante o transporte em containers refrigerados na exportação de maçãs. Quando os frutos foram deixados à temperatura ambiente, a utilização de um sachê de produto comercial foi eficiente na preservação da qualidade pós-colheita dos frutos, apenas em maçãs colhidas em estádio menos avançado de maturação. 

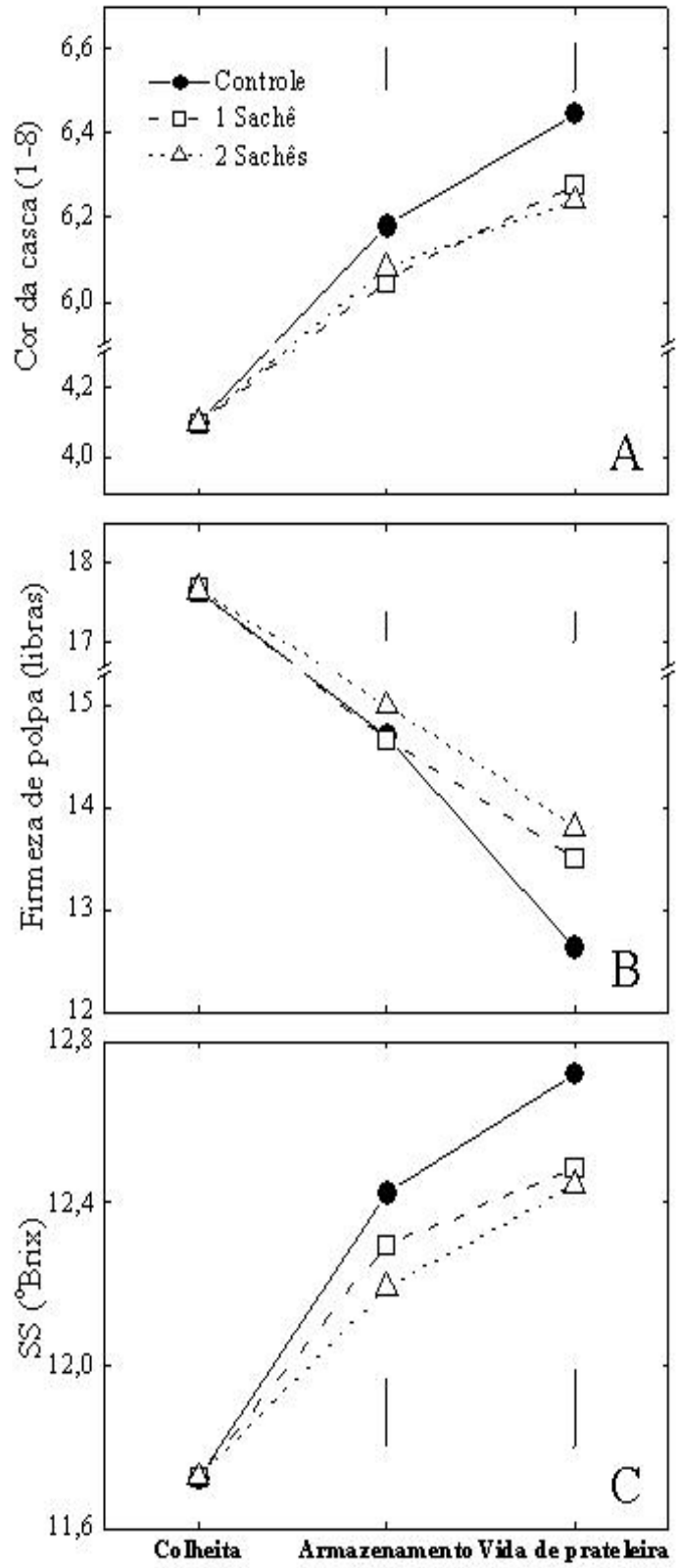

FIGURA 1- Valores de cor da casca (A), firmeza de polpa $(\mathbf{B})$ e sólidos solúveis (SS; C) em maçãs 'Royal Gala' acondicionadas em embalagens de polietileno, com (um ou dois) ou sem (controle) sachês de $\mathrm{KMnO}_{4}$, em caixas com $18 \mathrm{~kg}$ de frutos. Diferenças mínimas significativas (DMS) entre tratamentos, indicadas no interior da figura, foram calculadas pelo teste $\operatorname{LSD}(\mathrm{P}<0,05)$.
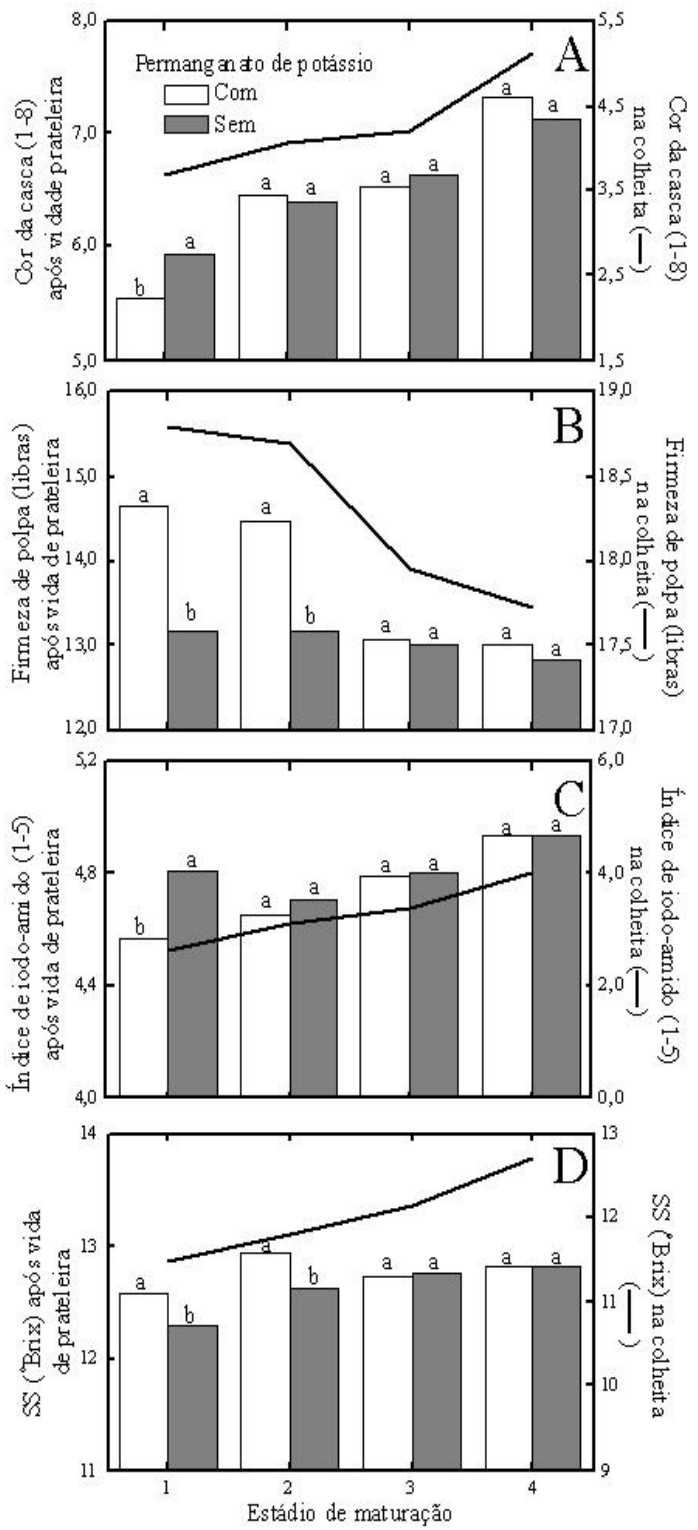

FIGURA 2- Cor da casca (A), firmeza de polpa (B), índice de iodo-amido $(\mathbf{C})$ e teor de sólidos solúveis ( $\mathrm{SS}$; D) em maçãs 'Royal Gala' colhidas em diferentes estádios de maturação (representado por linha cheia) e acondicionadas em embalagens de polietileno, com ou sem adição de um sachê de $\mathrm{KMnO}_{4}$, em caixas com $18 \mathrm{~kg}$ de frutos. Médias de tratamentos, para cada estádio de maturação, seguidas da mesma letra, não diferem significativamente pelo teste $\operatorname{LSD}(\mathrm{P}<0,05)$. 


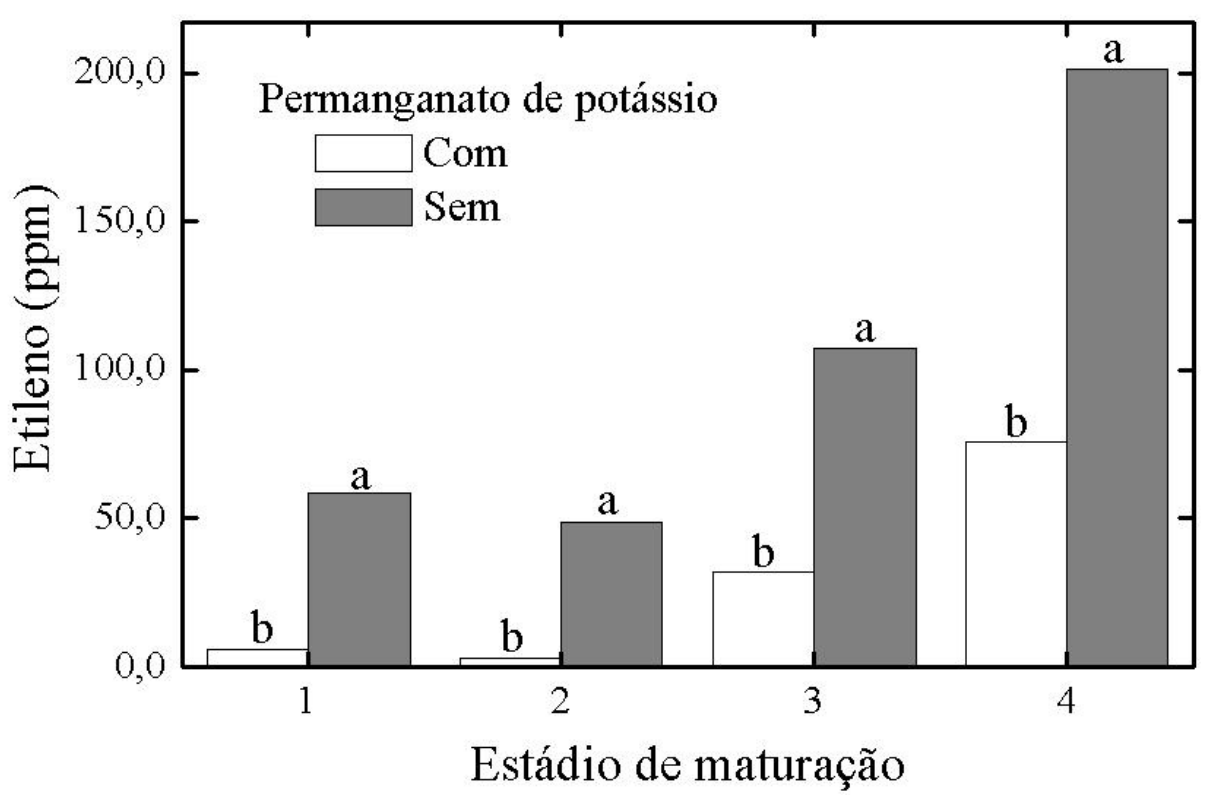

FIGURA 3- Concentração de etileno no interior de embalagens de polietileno, com ou sem sachê de $\mathrm{KMnO}_{4}$, em caixas com 18 kg, de maçãs 'Royal Gala' colhidas em diferentes estádios de maturação e mantidas durante sete dias em condição ambiente $\left(20 \pm 4^{\circ} \mathrm{C} / 70-80 \%\right.$ de UR). Médias de tratamentos, para cada estádio de maturação, seguidas da mesma letra, não diferem significativamente pelo teste LSD $(\mathrm{P}<0,05)$.

\section{CONCLUSÕES}

$\mathrm{O}$ uso de sachês de $\mathrm{KMnO}_{4}$ retardou o amadurecimento de maçãs 'Royal Gala' sob armazenamento refrigerado e também em temperatura ambiente, sendo que, neste último caso, o efeito é observado em frutos colhidos em estádios menos avançados de maturação.

\section{AGRADECIMENTOS}

Ao CNPq, pela concessão de Bolsa de Produtividade em Pesquisa ao primeiro autor.

\section{REFERENCIAS}

BRACKMANN, A.; MAZARO, S.M.; BORTOLUZZI, G. Qualidade da maçã 'Fuji' sob condições de atmosfera controlada. Ciência Rural, Santa Maria, v. 25, n.2, p.215-218, 1995.

BRACKMANN, A.; GIEHL, R.F.H.; FREITAS, S.T. de; EISERMANN, A.C.; MELLO, A.M. de. Uso de filmes de polietileno e absorção de etileno para o transporte refrigerado de maçã 'Gala'. Semina: Ciências Agrárias, Londrina, v.27, n.3, p.423-428, 2006.
CAMPOS, J.T. de; HASEGAWA, P.N.; PURGATTO, E.; LAJOLO, F.; CORDENUNSI, B.R. Qualidade póscolheita de nêsperas submetidas ao armazenamento sob baixa temperatura e atmosfera modificada. Ciência e Tecnologia de Alimentos, Campinas, v. 27, n. 2, p.401-407, 2007.

CHAUHAN, O.P.; RAJU, P.S.; DASGUPTA, D.K.; BAWA, A.S. Modified atmosphere packaging of banana (cv. Pachbale) with ethylene, carbon di-oxide and moisture scrubbers and effect on its ripening behaviour. American Journal of Food Technology, Vails Gate, v.1, n.2, p.179-189, 2006.

CHITARRA, M. I. F.; CHITARRA, A. B. Pós-colheita de frutas e hortaliças: fisiologia e manejo. 2. ed. Lavras: UFLA, 2005. 785p.

FERRI, V.C.; ROMBALDI, C.V. Resfriamento rápido e armazenamento de caquis (Diospyrus kaki, L.), cv. Fuyu, em condições de atmosfera refrigerada e modificada. Revista Brasileira de Fruticultura, Jaboticabal, v. 26, n.1, p.36-39, 2004.

ILLEPERUMA, C.K.; JAYASURIYA, P. Prolonged storage of 'Karuthacolomban' mango by modified atmosphere packaging at low temperature. Journal 
of Horticultural Science and Biotechnology, Kent, v.77, n.2, p.153-157, 2002.

ILLEPERUMA, C.K.; NIKAPITIYA, C. Extension of the postharvest life of 'Pollock' avocado using modified atmosphere packaging. Fruits, Paris, v.57, n.5/6, p.287-295, 2002.

KADER, A.A. Postharvest technology of horticultural products. $3^{\text {nd }}$ ed. Los Angeles: University of California, Division of Agriculture and Natural Resources, 2002. 535 p. (Publication, 3311).

RONGCAI, Y.; DAVID, H.C. Effects of NAA, AVG, and 1-MCP on ethylene biosynthesis, preharvest fruit drop, fruit maturity, and quality of 'Golden Supreme' and 'Golden Delicious' apples. Hortscience, Alexandria, v.42, n.1, p.101-105, 2007.

SHORTER, A.J.; SCOTT, K.J.; WARD, G.; BEST, D.J. Effect of ethylene absorption on the storage of 'Granny Smith' apples held in polyethylene bags. Postharvest Biology and Technology, Amsterdam, v.1, n.3, p.189-194, 1992.

SZCZERBANIK, M.J.; SCOTT, K.J.; PATON, J.E.; BEST, D.J. Effects of polyethylene bags, ethylene absorbent and 1-methylcyclopropene on the storage of Japanese pears. The Journal of Horticultural Science \& Biotechnology, Kent, v. 80, n.2, p.162$166,2004$.
WATKINS, C.B. The use of 1-methylcyclopropene (1-MCP) on fruits and vegetables. Biotechnology Advances, Amsterdam, v.24, n.4, p.389-409, 2006.

WILLS, R. H.; MCGLASSON, W. B.; GRAHAM, D.; JOYCE, D. Postharvest, an introduction to the physiology and handling of fruit, vegetables and ornamentals. $4^{\text {th }}$. ed. New York: CAB International, 1998. 262 p.

WILLS, R.B.H.; WARTON, M.A.; MUSSA, D.M.D.N.; CHEW, L.P. Ripening of climacteric fruit initiated at low ethylene levels. Australian Journal of Experimental Agriculture, Victoria, v.41, n.1, p. 89-92, 2001.

WILLS, R.B.H.; WARTON, M.A. Efficacy of potassium permanganate impregnated into alumina beads to reduce atmospheric ethylene. Journal of the American Society for Horticultural Science, Alexandria, v.129, n.3, p.433-438, 2004.

ZHANG, Y. Combined technology of kiwifruit storage and freshness-keeping with freshness-keeping reagent at low temperature and modified atmosphere. Transactions of the Chinese-Society of Agricultural Engineering, Beijing, v.18, n.4, p.138-141, 2002. 